\title{
Gastrointestinal Parasites in Road-Killed Raccoons and Opossums in Western Maryland
}

\author{
Ainsley Raley ${ }^{\mathrm{a}}$, Rebecca Price ${ }^{\mathrm{a}}$, Dr. William L. Seddon ${ }^{\mathrm{a}}$, and Dr. Karen L. Keller ${ }^{\mathrm{a}}$
}

\begin{abstract}
Opossums (Didelphis virginiana) and raccoons (Procyon lotor) harbor several types of endoparasites, including various nematode and cestode species. The purpose of this study was to identify endoparasites from the gastrointestinal tract of roadkilled opossums and raccoons collected in fall 2011 in Allegany and Garrett counties in Maryland. A total of 2 opossums and 3 raccoons were collected and dissected and several endoparasitic worms were removed. Sex of each worm was determined and eggs were removed from selected females for examination. Two nematode species were identified in the opossum: Physaloptera turgida was found in the stomach; and Cruzia americana was found in the intestine. One nematode species was identified in the raccoon: Baylisascaris procyonis was found in the intestine. Also, approximately 12 damaged proglottids from a tapeworm were found in the intestine of 1 raccoon, but definitive identification of the species was not possible. Our results are similar to previous studies which have found these same nematodes in opossums and raccoons, although recent reports of these species in Western Maryland have not been reported. Endoparasite species are usually specific to their definitive host; however, $B$. procyonis is considered a zoonotic agent because accidental ingestion of eggs can cause visceral larval migrans in humans. Even though our sample size was too small to assign any statistical significance to our data, the fact remains that B. procyonis poses a serious risk to human health and further studies to determine the number of raccoons and other animals infected in Western Maryland may be warranted.
\end{abstract}

Keywords: Raccoons, Opossums, Endoparasites, Nematodes

\section{Introduction}

Opossums (Didelphis virginiana) and raccoons (Procyon lotor) are known to harbor several types of ectoparasites and endoparasites. Ectoparasites, such as fleas and ticks, move from host to host, but endoparasites, such as nematodes (roundworms) and cestodes (tapeworms) live inside the animal, so they are frequently host-specific and may also be organ-specific. For example, two endoparasite species commonly found in opossums are nematodes, and include Physaloptera (Turgida) turgida and Cruzia americana (5, 6, 7, 9, and 10). P. turgida is usually found in the lumen of the stomach or attached to the gastric mucosa, while $C$. americana is usually found in the lumen of the intestines and cecum $(6,7$, and 9). One common nematode of raccoons is Baylisascaris procyonis, which is found primarily in the lumen of the small intestine or attached to the intestinal mucosa $(2,4,11,13$, and 14).

All 3 of these nematodes are normal parasites in their particular hosts and rarely cause excessive damage to the stomach or intestines unless infection rates are very high or other stressors, such as malnutrition or other illness, weaken the animal $(2,5,6,7,9$, and 13). Also, there is little evidence to suggest that $P$. turgida or $C$. americana can use any animal other than the opossum as their definitive host. On the other hand, when eggs from B. procyonis are ingested by any animal other than a raccoon, the larval form hatches and migrates out of the intestine to other body organs, such as the brain. This is called visceral larval migrans and affects many animal species, including humans $(2,4,8,11,13$, and 14). If the larvae do migrate to the brain, the resulting encephalitis is very dangerous and may be fatal in young children (2 and 8). The main goal of our study was to determine whether the commonly identified parasites described above are currently infecting opossums and raccoons in Western Maryland. We chose to dissect road-killed animals rather than trapping and euthanizing live animals for our study because it is possible to identify most endoparasites without sacrificing live animals.

\section{Materials and Methods}

In fall 2011, 2 road-killed opossums and 3 road-killed raccoons were collected from roadways in Allegany and Garrett Counties in Maryland. The animals were carefully dissected and all internal organs were visually examined for evidence of parasitic infection. The gastrointestinal tract was then removed for a thorough examination of the lumen. Parasites found in the stomach, small intestine, and large intestine were identified to species using characteristics of the anterior ends of the worms, which are similar between male and female worms, and the posterior ends, which differ between the sexes. In addition, selected female worms were dissected and eggs were removed for examination. All specimens were placed in labeled vials containing $70 \%$ isopropanol. Photographs were taken of the anterior end, the posterior end of males and females, and eggs of each species of parasite.

\section{Results}

Both opossums were infected with parasites. P. turgida was found in the stomach lumen of both animals and $C$. americana was found in the small intestine lumen of both animals and the large intestine lumen of opossum 1 . No attachment lesions were found on the stomach or intestinal muscosa. Male and female nematodes from both parasite species were found in both opossums. A total of 180 parasites were found in opossum 1 and 20 parasites were found in 
opossum 2 (Table 1). Although 2 of the nematodes found in the second opossum were torn, enough of each worm was recovered that identification and sexing were possible, so these specimens are included in the totals. Photographs of the anterior end and the posterior ends of male and female $P$. turgida and $C$. americana as well as eggs removed from a female of each species are seen in Figures 1 and 2.

All 3 raccoons were infected with parasites. B. procyonis was found in the small intestine lumen of raccoons 1 and 3 and the large intestine lumen of raccoon 1 . No attachment lesions were found on the intestinal mucosa. Male and female nematodes of $B$. procyonis were found in both raccoons with this parasite. Approximately 12 damaged proglottids from a tapeworm were found in the intestine of raccoon 2, but definitive identification of the species was not possible. A total of 7 parasites were found in raccoon 1, 1 parasite in raccoon 2, and 31 parasites in raccoon 3 (Table 1). Photographs of the anterior end and the posterior ends of male and female B. procyonis and eggs removed from a female specimen are seen in Figure 3.

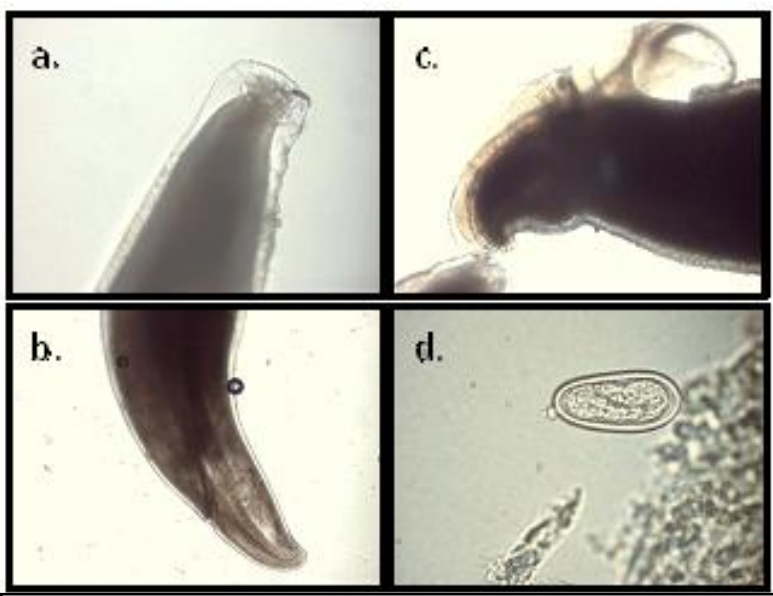

Figure 1: Physaloptera turgida

a. Anterior end [200X]; b. Posterior end (female) [200X]; c. Posterior end (male) [200X]; d. Eggs [400X]

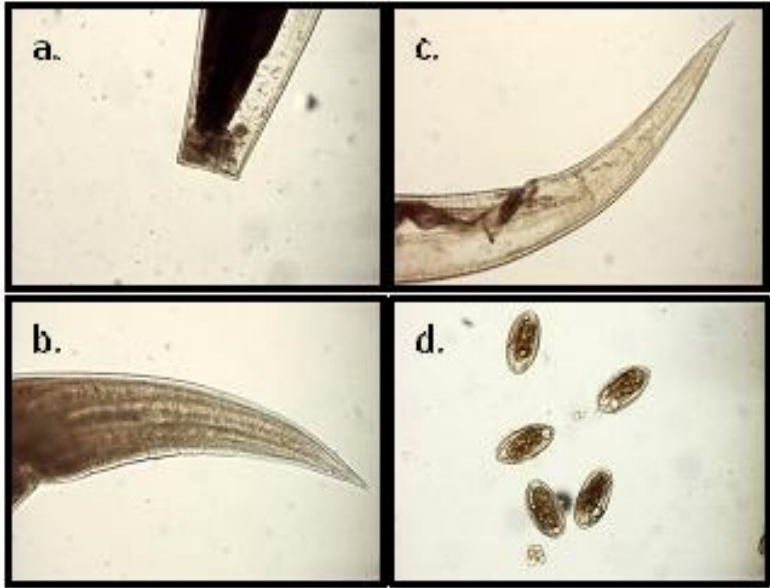

Figure 2: Cruzia americana

a. Anterior end [200X]; b. Posterior end (female) [200X]; c. Posterior end (male) [200X]; d. Eggs [400X]

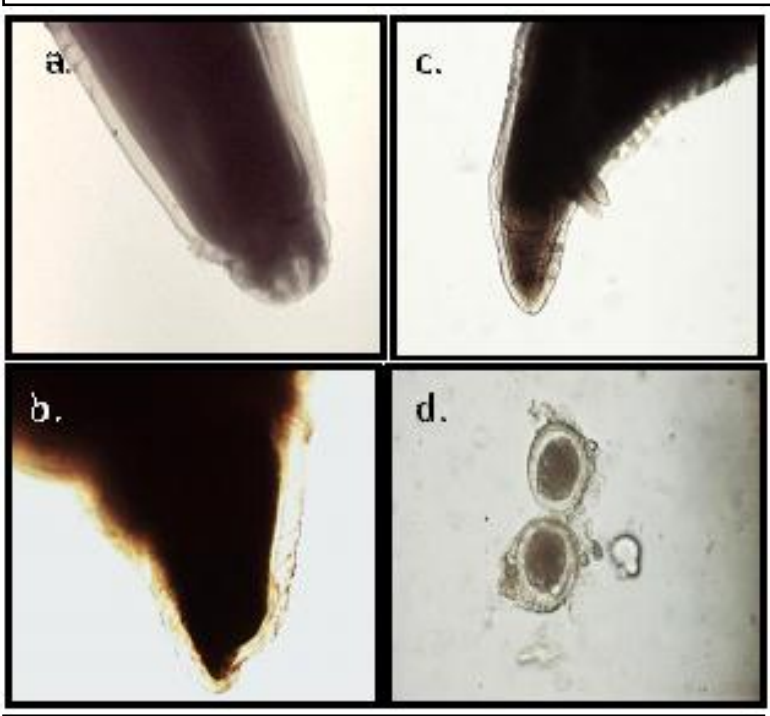

Figure 3: Baylisascaris procyonis

a. Anterior end [4X]; b. Posterior end (female) [100X]; c. Posterior end (male) [100X]; d. Eggs [400X]

Table 1: Parasite Number and Location from Road-Killed Opossums and Raccoons

\begin{tabular}{cccccccc}
$\begin{array}{c}\text { Region of } \\
\text { GI Tract }\end{array}$ & \multicolumn{2}{c}{ Stomach } & \multicolumn{2}{c}{ Small Intestine } & \multicolumn{2}{c}{ Large Intestine } & \\
$\begin{array}{c}\text { Sex of } \\
\text { Parasite }\end{array}$ & Males & Females & Males & Females & Males & Females & $\begin{array}{c}\text { Total Parasite } \\
\text { Number }\end{array}$ \\
Opossum 1 & 57 & 10 & 5 & 1 & 19 & 88 & 180 \\
Opossum 2 & 14 & 4 & $1 *$ & $1 *$ & 0 & 0 & 20 \\
Raccoon 1 & 0 & 0 & 3 & 0 & 0 & 4 & 1 \\
Raccoon 2 & 0 & 0 & 0 & $1 \dagger$ & 0 & 0 & 31 \\
Raccoon 3 & 0 & 0 & 3 & 28 & 0 & 0 & 1 \\
\hline
\end{tabular}

* Partial pieces of nematodes were recovered; however, they were positively identified as 2 separate nematodes.

$\dagger$ Approximately 12 damaged proglottids of an unidentified tapeworm were recovered.

Although male and female gonads are present, it is listed in the female column. 


\section{Conclusions}

Our results are similar to previous studies which found both $P$. turgida and $C$. americana in the gastrointestinal tract of opossums $(5,6,7,9$, and 10$)$ and $B$. procyonis in the intestine of raccoons $(2,4,11,13$, and 14). However, only one of these studies collected animals from Maryland (7) and this study was limited to opossums.

The single parasite found in raccoon 2 was a tapeworm; however, only approximately 12 damaged proglottids were recovered and definitive identification without a scolex and intact proglottids was not possible. It is possible that the tapeworm was either Atriotaenia procyonis or Mesocestoides variabilis, as these are the most commonly reported tapeworms found in raccoons (1, 3, and 12).

Although we were able to determine that $P$. turgida, $C$. americana and $B$. procyonis are currently infecting opossums and raccoons in Western Maryland, our sample size was too small to assign any statistical significance to our data. The fact remains; however, that $B$. procyonis poses a serious human health risk and it has been positively identified in raccoons in Western Maryland. Further studies to determine the number of raccoons and other animals infected may be warranted.

\section{Acknowledgements}

We would like to thank Frostburg State University for support of this research. Animals were collected under the supervision of Dr. Thomas Lambert, Assistant Professor of Biology, Frostburg State University (Scientific Collection Permit \# 50003, State of Maryland).

\section{Literature Cited}

1. Bafundo, K.W., Wilhelm, W.E. and Kennedy, M.L. 1980. Geographic variation in helminth parasites from the digestive tract of Tennessee raccoons, Procyon lotor. $\mathrm{J}$ Parasitol. 66(1):134-139.

2. Blizzard, E.L., Davis, C.D., Henke, S., Long, D.B., Hall, C.A. and Yabsley, M.J. 2010. Distribution, prevalence, and genetic characterization of Baylisascaris procyonis in selected areas of Georgia. J Parasitol. 96(6): 11281133.

3. Cole, R.A. and Shoop, W.L. 1987. Helminths of the raccoon (Procyon lotor) in western Kentucky. J Parasitol. 73(4):762-768.

4. Chavez, D.J., LeVan, I.K., Miller, M.W., and Ballweber, L.R. 2012. Baylisascaris procyonis in raccoons (Procyon lotor) from eastern Colorado, an area of undefined prevalence. Vet Parasitol. 185(2-4):330-334.

5. Feldman, D.B., Moore, J.A., Harris, M.W., and Self, J.L. 1972. Characteristics of common helminths of the Virginia opossum (Didelphis virginiana) from North Carolina. Lab Anim Sci. 22:183-189.

6. Gray, J.B., and Anderson, R.C. 1982. Observations on Turgida turgida (Rudolphi, 1819) (Nematoda: Physalopteroidea) in the American opossum (Didelphis virginiana). J Wildl Dis. 18:279-285.

7. Keller, K.L., Harman, A.L., and Harman, D. 1997. Incidence of Physaloptera turgida (Rudolphi, 1819) in the Virginia opossum (Didelphis virginiana Kerr, 1792). Maryland Naturalist. 41(1-2):35-44.

8. Murray, W.J., and Kazacos, K.R. 2004. Raccoon roundworm encephalitis. Emerging Infections 39:14841492.

9. Nichelason, A.E., Rejmanek, D., Dabritz, H.A., Melli, A.C., Miller, M., and Conrad, P.A. 2008. Evaluation of Cruzia americana, Turgida turgida, and Didelphostrongylus hayesi infection in the Virginia opossum (Didelphis virginiana) and risk factors along the California coast. J Parasitol. 94(5):1166-1168.

10. Nettles, V.F., Prestwood, A.K., and Davidson, W.R. 1975. Severe parasitism in an opossum. J Wildl Dis. 11:419-420.

11. Reed, C., Henke, S.E., and Kresta, A.E. 2012. Frequency of deposition and location of Baylisascaris procyonis eggs in raccoon feces. J Wildl Dis. 48(1):190-194.

12. Richardson, D.J., Owen, W.B. and Snyder, D.E. 1992. Helminth parasites of the raccoon (Procyon lotor) from north-central Arkansas. J Parasitol. 78(1):163-166.

13. Samson, A., Dubay, S., Huspeni, T.C., and Cyr, A. 2012. Influence of environmental variables on Baylisascaris procyonis infection in raccoons. J Parasitol. (Epub ahead of print).

14. Yeitz, J.L., Gillin, C.M., Bildfell, R.J., and E.E. DeBess. 2009. Prevalence of Baylisascaris procyonis in raccoons (Procyon lotor) in Portland, Oregon, USA. J Wildl Dis. 45(1):14-18. 